\title{
Evaluating the Impact of Social Deprivation on Press Ganey® Outpatient Medical Practice Survey Scores
}

\section{Andrew R Stephens ( $\sim$ andrew.stephens@hsc.utah.edu )}

University of Utah Hospital https://orcid.org/0000-0003-3877-7723

Jared W Potter

University of Utah Hospital

Andrew R Tyser

University of Utah Hospital

Nikolas H Kazmers

University of Utah Hospital

\section{Research}

Keywords: Satisfaction, social deprivation, socioeconomic, access to healthcare

Posted Date: November 3rd, 2020

DOI: https://doi.org/10.21203/rs.3.rs-22294/v2

License: (c) (i) This work is licensed under a Creative Commons Attribution 4.0 International License. Read Full License

Version of Record: A version of this preprint was published at Health and Quality of Life Outcomes on June 19th, 2021. See the published version at https://doi.org/10.1186/s12955-020-01639-y. 


\section{Abstract}

Background: Social deprivation has been shown to affect access to health care services, and influences outcomes for a variety of physical and psychological conditions. However, the impact on patient satisfaction remains less clear. The objective of this study was to determine if social deprivation is an independent predictor of patient satisfaction, as measured by the Press Ganey ${ }^{\circledR}$ Outpatient Medical Practice Survey (PGOMPS).

Methods: We retrospectively reviewed unique new adult patient ( $\geq 18$ years of age) seen at a tertiary academic hospital and rural/urban outreach hospitals/clinics between January 2014 and December 2017. Satisfaction was defined a priori as achieving a score above the $33^{\text {rd }}$ percentile. The 2015 Area Deprivation Index (ADI) was used to determine social deprivation (lower score signifies less social deprivation). Univariate and multivariable binary logistic regression were used to determine the impact of ADI on PGOMPS total and provider sub-scores while controlling for variables previously shown to impact scores (wait time, patient age, sex, race, specialty type, provider type, and insurance status).

Results: Univariate analysis of PGOMPS total scores revealed a $4 \%$ decrease in odds of patient satisfaction per decile increase in ADI $(p<0.001)$. Patients within the most deprived quartile were significantly less likely to report satisfaction compared to the least deprived quartile (OR $0.79, p<0.001)$. Multivariable analysis revealed that the odds of achieving satisfaction decreased $2 \%$ for each decile increase in ADI on the Total Score $(p<0.001)$, independent of other variables previously shown to impact scores. For PGOMPS Provider Sub-Score, univariate analysis showed that patients in the lowest ADI quartile were significantly less likely be satisfied, as compared to the least deprived quartile (OR 0.77; $95 \%$ $\mathrm{Cl} 0.70$ to $0.86 ; p<0.001)$. A $5 \%$ decrease in a patient being satisfied was observed for each decile increase in $\mathrm{ADI}(\mathrm{OR} 0.95 ; 95 \% \mathrm{Cl} 0.94$ to $0.96 ; \mathrm{p}<0.001)$.

Conclusions: Social deprivation was an independent predictor of outpatient visit dissatisfaction, as measured by the Press Ganey ${ }^{\circledR}$ Outpatient Medical Practice Survey. These results necessitate consideration when developing health care delivery policies that serve to minimize inequalities between patients of differing socioeconomic groups.

\section{Background}

Social deprivation incorporates not only socioeconomic status (SES), but also includes a person's education level, social standing, and access to resources that are available to the general population. The impact of social deprivation on patient health has been well documented. Individuals with greater levels of social deprivation are at an increased risk of major diseases including cardiovascular conditions (1-3), diabetes (4), cirrhosis (5), hypertension (6,7), and an increased incidence of trauma (8-10). Similarly, lower SES has been correlated with a worse prognosis and a greater likelihood of disease progression for a variety of conditions, and a higher rate of surgical complications (11-20). Lower SES also affects access to health care services including preventative screening (21) and surgical or procedural 
interventions (22-25). Higher levels of social deprivation are also associated with worse patient-reported functional and psychological outcomes (26-31).

Specific to patient satisfaction, social deprivation has been associated with lower satisfaction on metrics including the Hospital Consumer Assessment of Healthcare Providers and Systems Survey (HCAHPS), the English General Practice Survey, the General Practice Assessment Survey, the National Research Corporation Healthcare Market Guide Survey, and the Primary Care Assessment Tool, and the Kaiser National Household Survey (32-38).

The Press Ganey ${ }^{\circledR}$ Outpatient Medical Practice Survey (PGOMPS) is another commonly used survey utilized to measure patient satisfaction with the process of outpatient care delivery that has been utilized for over 30 years, and is increasingly used by health care systems across the United States. Previous work has demonstrated that PGOMPS is susceptible to a high ceiling rate (29\%) similar to findings for other patient satisfaction surveys such as HCAHPS. PGOMPS was also demonstrated to have high internal consistency reliability ( 0.79 to 0.96$)$ and convergent validity.(39) Although Nieman et al. demonstrated that lower socioeconomic status correlated with worse PGOMPS scores among the pediatric surgical population (40), we are unaware of reports evaluating the effects of socioeconomic status on PGOMPS scores across a large multidisciplinary health care system, or literature assessing for an impact of social deprivation on PGOMPS scores.

Our primary study aim was to determine whether social deprivation is associated with patient satisfaction as measured by the PGOMPS Total Score. The secondary aim was to determine the impact of social deprivation on a patient's satisfaction with their provider, as measured by the PGOMPS Provider Sub-Score. Our null hypotheses are that social deprivation does not impact patient satisfaction scores as measured by the PGOMPS Total Score and the Provider Sub-Score.

\section{Methods}

Our institutional review board approved this retrospective study. Our institution has contracted with Press Ganey Corporation to prospectively collect patient satisfaction scores connected to all outpatient encounters, and evaluates these scores in attempt to improve care delivered. Following each outpatient visit, an e-mail is sent to a patient requesting they complete the PGOMPS. If the survey is incomplete after 5 days, an additional email reminder is sent. Patients may access the survey for up to 30 days post-visit. The Press Ganey Corporation compiles the survey scores, then reports the Total Scores and Provider SubScores back to our institution. Score calculation is performed by the Press Ganey Corporation using proprietary algorithms.

PGOMPS questions are measured on a Likert scale ranging from 1 (indicating very poor) to 5 (indicating very good) and are converted to a $0-100$ scale. The survey is comprised of six subdomains: access, moving through your visit, nurse or assistant, care provider, personal issues, and overall assessment for a total of 25 questions and the Total Score is calculated from the mean scores from each of these six 
individual subdomains using proprietary equations (41). Similarly, a Provider Sub-Score is computed from the provider-specific questions.

We considered for inclusion all adults ( $\geq 18$ years of age) presenting to a single tertiary academic medical center for a new, outpatient visit seen by physicians, physicians assistants (PA), or nurse practitioners (NP) between January 2014 and December 2017 with a completed Press Ganey Survey, and residence within the state of Utah. Only first new (to the specific provider) patient visits were included, and return and postoperative patient visits were excluded. Patients with incomplete surveys that precluded calculation of a Total Score, a primary language other than English, those lacking a listed address, and those with only a listed post office box, were excluded. Additionally, patients who reported waiting over 6 hours to be seen by their provider were excluded as this likely to represent a data entry error. Providers with less than 30 Total Score responses were excluded, given that this small sample size has been stated by the Press Ganey Corporation to lead to inadequate validity (42).

Inclusion also required a 2015 Area Deprivation Index (ADI) value in order to quantify social deprivation for each patient (43). Therefore, patients with a Post Office Box address were excluded, as a specific ADI cannot be calculated. The ADI value encompasses 17 socioeconomic status factors, including variables such as income, education level, and housing type, that are taken into consideration when assigning ADI scores for a given Zip+4 code, and provides a percentile score on a national basis (44). Zip+4 codes covers an average of 10 to 20 homes $(45,46)$. Health Resources and Services Administration census data was used in the initial development of ADI and the scores are regularly updated to include the most recent American Community Survey data.(46, 47) ADI has been utilized in several previous studies $(30,31,44$, $46,48-54)$, and a higher percentile represents a greater level of social deprivation.

Eligible patient visits were identified by electronic data acquisition of their associated PGOMPS scores and corresponding demographic and visit characteristic data. Wait times in the waiting room and exam room are estimated by the patient after the visit when they complete the survey. The total wait time was calculated as the sum of these two estimates. Satisfaction was defined a priori as receiving a score greater than the $33^{\text {rd }}$ percentile, as per prior studies $(41,55-57)$.

Continuous variables were summarized as mean \pm standard deviation (SD) and categorical variables were summarized as count and percentages (\%). The median and interquartile range were calculated for ADI. Potential associations between predictor variables and Total or Provider Sub-Score was identified by univariate binary logistic regression. Separate univariate binary logistic regression models were run with $A D I$ as a continuous variable to predict odds of satisfaction, and categorically by comparing patients in top (scores of 76-100) versus bottom (scores of 0-24) quartiles for ADI on a national level. Provider specialty type was categorized into one of three divisions: internal medicine, surgical, or other. 'Other' specialty type was defined as any non-surgical specialty that did not necessitate an internal medicine residency (neurology, dermatology, anesthesiology, etc). Predictor variables such as patient age, sex, and race, total wait time, specialty type, provider type (physician, nurse, PA, and other), and insurance (commercial, Medicare, Medicaid, workers' compensation and other government insurance) were 
analyzed. Multivariable binary logistic regression models with backward stepwise term selection (cutoff a $=0.1$ ) were then used to determine factors associated with Total and Provider Sub-Score satisfaction, as defined by exceeding versus not exceeding the $33^{\text {rd }}$ percentile score, using predictor variables found to be significant in the respective univariate analyses.

\section{Results}

A total of 61,698 new patient visits with associated PGOMPS Total Scores were identified during our study period. The following exclusions were made: 1117 patients for not having an available ADI, 610 patients for a primary language other than English, and 16 for reported wait times $>6$ hours. Of the 59,955 included patients, mean age was $51.7 \pm 17.1$ years, $59.3 \%$ were female and $90.5 \%$ were White. The PGOMPS Total Score averaged $91.4 \pm 12.0$ with a $33^{\text {rd }}$ percentile cutoff of 91.7 (Figure 1). A mean of $93.1 \pm 14.8$, and $33^{\text {rd }}$ percentile cutoff of 97.5 , were observed for the Provider Sub-Score. Mean ADI was $30.8 \pm 19.2$ (median 28.0; interquartile range 17.0 to 42.0 ; range 1 to 100 ; Figure 2). Additional patient demographics and visit data are listed in Table 1.

Univariate analysis showed that patients in the most deprived quartile were significantly less likely be satisfied, as compared to the least deprived quartile, for the PGOMPS Total Score (OR 0.79; $95 \% \mathrm{Cl} 0.71$ to $0.87 ; p<0.001$ ). For each decile increase in ADI, the likelihood of a patient being classified as satisfied decreased by an OR of 0.96 (95\% $\mathrm{Cl} 0.95$ to $0.96 ; p<0.001$; Table 2). The PGOMPS Total Score was found to be significantly associated with patient age, sex, race, insurance status, wait time. Provider type and specialty type had no statistically significant correlation with the Total Score (Table 2).

For the PGOMPS Provider Sub-Score, univariate analysis showed that patients in the lowest ADI quartile were significantly less likely be satisfied, as compared to the least deprived quartile (OR $0.77 ; 95 \% \mathrm{Cl} 0.70$ to $0.86 ; p<0.001)$. For each decile increase in ADI, there was a decrease in the likelihood of a patient being satisfied by an OR of 0.95 ( $95 \% \mathrm{Cl} 0.94$ to 0.96 ; $p<0.001$; Table 3$)$. Scores also correlated patient age, race, insurance status, wait time, provider type, and specialty type. Patient sex had no statistically significant association with the Provider Sub-Scores (Table 3).

Multivariable analysis revealed a significant negative association between satisfaction on the PGOMPS Total Score and ADI. This was independent of patient age, specialty type, provider type, race, and wait time. Specifically, for each decile increase in ADI the likelihood of achieving satisfaction was decreased by an OR of $0.98(95 \% \mathrm{Cl}, 0.97$ to $0.99 ; \mathrm{p}<0.001$; Table 4). Multivariable analysis also revealed a significant negative association between the PGOMPS Provider Sub-Score and ADI which was independent of patient age, specialty type, provider type, race, and wait time such that achieving satisfaction decreased by and OR of 0.97 ( $95 \% \mathrm{Cl} 0.96$ to $0.98 ; p<0.001$; Table 5) for each decile increase in $A D I$.

\section{Discussion}


The main finding of this study was that increased social deprivation was associated with decreased outpatient satisfaction, as measured by the Press Ganey Outpatient Medical Practice Survey. This observation was observed for both the Press Ganey Total Score and the Provider Sub-Score, and was independent of several factors previously shown to have a large magnitude of impact on patient satisfaction including wait time, patient age, sex and race $(41,55,57,58)$. The secondary findings of the study are in-line with much prior work on patient satisfaction and associated factors such as patient age, sex, race, insurance status, wait time, provider type, and specialty type. $(41,55,57,58)$

The importance of understanding how socioeconomic factors affect the utilization of and access to the healthcare system is becoming increasingly evident. The role of a patient's social and economic circumstances in their overall physical and mental health has been well-elucidated $(3,11,31,46,48,53$, 58-60), and our findings are consistent with a limited number of previous studies in documenting an association between socioeconomic status and patient satisfaction scores.

Young et al. demonstrated that average income levels based on zip codes and lower patient satisfaction scores are correlated among elderly patients seen in various specialty clinics (61). McFarland et al. evaluated 934,000 patients and showed Hospital Consumer Assessment of Healthcare Providers and Systems (HCAHPS) survey scores were directly correlated with education level, which has been used as a surrogate for socioeconomic status in the literature (38). Additionally, Nieman et al. demonstrated that lower socioeconomic status correlated with worse PGOMPS scores among the pediatric surgical population (40).

Critically, this study does not address whether the quality of health care differed based on a patient's social deprivation. The PGOMPS does not measure health care quality, but rather satisfaction with the process of outpatient health care provision. It is important to make the distinction between quality and satisfaction, particularly when interpreting evidence suggesting that social deprivation may influence a patient's perception of the care they received $(22,62-65)$. Along those lines, this study does not address the underlying causes of differences in patient satisfaction scores between patients with different levels of social deprivation. Arpey et al. demonstrated that patients of lower SES were more likely to perceive their economic status as influencing their care than those of higher socioeconomic brackets (62).

Verlinde et al. conducted a systematic review evaluating how SES affects physician patient communication. In their study they found that patients of lower SES are less likely to participate in shared decision making and ask questions (66). Schroder et al. pointed out that patients in the bottom socioeconomic quartile had less medical knowledge and were less likely to desire to play an active role in their disease management than patients in the highest quartile (67). Studies by Wright et al. and Okoroafor et al. demonstrated that patients were more likely to report high levels of anxiety and depression in worse social deprivation indexes $(30,31)$, and Tyser et al. and Tisano et al. independently showed that patients with worse PROMIS anxiety and depression scores were less likely to report satisfaction on the PGOMPS $(58,68)$. An additional study by Schroder et al. found that patients of lower SES were more likely to wait to seek care for their heart disease until after they suffered a myocardial 
infarction (69). Previous literature has also shown that physicians who treat patients with greater disease severity and worse prognosis are more likely to receive lower patient satisfaction scores (70-73).

Objective discrepancies of care based on socioeconomic status have, however, been documented. Govindarajan and Schull found that patients residing in economically deprived neighborhoods were less likely to have advanced paramedic teams dispatched to their location and had greater transport time to hospitals when controlled for distance than those residing in less economically deprived neighborhoods (24). Patel et al. found that time between initial encounter for an ACL tear to surgery was greater for pediatric patients from lower socio-economic settings (23). The systematic review conducted by Verlinde et al. also found that lower SES patients received less overall communication and fewer explanations directed to their understanding level than those of higher SES (66). It remains uncertain if these inequalities of care are a result of limited access of care and insurance/payment difficulties, or rather due to inherent biases. Clearly, the interplay between socioeconomic status, social deprivation, and the healthcare delivery process is complex. Further work is needed to evaluate for and potentially reduce discrepancies of care that these patients may experience in line with the overall goal of providing equitable and high-quality care.

The Patient Protection and Affordable Care Act enables Medicare to make incentive payments to hospitals based on specific quality domains that include the patient experience of care, and have in turn been used to adjust physician compensation $(74,75)$. Our findings may also help inform health care policy makers and/or administrators in decision making surrounding attaching patient satisfaction scores to various methods of reimbursements. The impact of such policies should be evident: without accounting for the impact of a patient's economic disadvantage on satisfaction scores, providers who have reimbursement tied to satisfaction scores may be disincentivized from caring for patients with, or working in areas with, high levels social deprivation. This could further perpetuate the disparities that these policies are attempting to correct. An example of this was demonstrated in a study that evaluated the impact of the 2019 peer group stratification of Medicare's Hospital Readmission Reduction Program (HRRP) in the United States. The HRRP allows for a penalization to be enacted if hospitals have readmission rates greater than 30 days (76). In 2016, The United States Congress passed the $21^{\text {st }}$ Century Cures Act allowing HRRP to take into consideration the effect of social deprivation on readmission rates (77). Under HRRP in 2019, hospital performance was stratified into quintiles based on patient socioeconomic status and the proportion enrolled in Medicare and Medicaid. The cost of readmission penalties to hospitals and subsequently physician reimbursements were cut in half for hospital's in the most deprived quintile as demonstrated by Joynt Maddox et al (78). The importance of accounting for SES in evaluation of health care quality has also been demonstrated outside of the United States.(79)

There are several limitations of this study. The generalization of our findings to other health care systems with differing regional and patient demographics is limited given that our study was conducted at a single institution treating a population that is predominately white. Furthermore, our institution provides care for patients from a large geographical distribution. Many patients, often from underserved and economically disadvantaged areas, travel up to several hours to be seen by specialists at our institution. 
The expectations, and therefore satisfaction, of these patients be different from other hospital systems with smaller catchment areas. Our study is also limited by a non-response bias, which is also an inherent limitation of the PGOMPS in general. Previous literature from our institution has shown the PGOMPS response rate to ranges from 8.9 to $16.5 \%(39,41)$. Tyser et al. found that responders differed from nonresponders in terms of age, sex, and insurance type (56). These factors are a real-world limitation of PGOMPS, and should not only be taken into account when interpreting study results, but also when determining the applicability of the survey as a determinant of vale of care and reimbursement rates. Although we only included new patient visit patient encounters, it is possible that a patient's economic situation, and satisfaction with care, could potentially change throughout a treatment course. Lastly, the magnitude the association between ADI and satisfaction are seemingly small in comparison to patient age and wait time, but the effects are additive for increasing deciles of social deprivation and the comparison between highest and lowest quartiles demonstrates a significant difference.

\section{Conclusion}

Increased social deprivation is a predictor of lower patient satisfaction, as measured by the Press Ganey Outpatient Medical Practice Survey, and this effect is independent of other known factors that have a large impact on scores. These results necessitate consideration in order to develop health care delivery policies that serve to minimize inequalities between patients of differing socioeconomic groups.

\section{Abbreviations}

socioeconomic 283 status (SES), Hospital Consumer Assessment of Healthcare Providers and Systems Survey (HCAHPS), Press Ganey ${ }^{\circledR}$ Outpatient Medical Practice Survey (PGOMPS), nurse practicioner (NP), physician assistant (PA), and Area Deprivation Index (ADI).

\section{Declarations}

Availability of Data and Materials: We do not feel that it is appropriate to publish the raw data used to perform this study, as it is largely proprietary and administered by a private corporation. The data can be available from the authors upon request.

Competing interests: The authors declare that they have no competing interests.

Consent for publication: Not applicable.

Ethics approval and consent to participate: This study was reviewed and approved by the University of Utah institutional review board (IRB). Consent was not required for this minimal risk, retrospective study, based on review by the IRB.

Funding: None 
Author's Contribution: AS participated in the study design, data collection, and drafted the manuscript. JP participated in the data collection and reviewed and edited the manuscript. AT participated in the study design and reviewed and edited the manuscript. NK conceived the study idea and participated in the statistical design, performed the statistical analysis, and helped draft the manuscript. All authors read and approved of the final manuscript.

\section{Acknowledgments: None}

\section{References}

1. Pujades-Rodriguez M, Timmis A, Stogiannis D, Rapsomaniki E, Denaxas S, Shah A, et al. Socioeconomic deprivation and the incidence of 12 cardiovascular diseases in 1.9 million women and men: implications for risk prediction and prevention. PLoS One. 2014;9(8):e104671.

2. Tunstall-Pedoe $\mathrm{H}$, Woodward $\mathrm{M}$, estimation Sgor. By neglecting deprivation, cardiovascular risk scoring will exacerbate social gradients in disease. Heart. 2006;92(3):307-10.

3. Rosengren A, Smyth A, Rangarajan S, Ramasundarahettige C, Bangdiwala SI, AlHabib KF, et al. Socioeconomic status and risk of cardiovascular disease in 20 low-income, middle-income, and highincome countries: the Prospective Urban Rural Epidemiologic (PURE) study. Lancet Glob Health. 2019;7(6):e748-e60.

4. Suwannaphant K, Laohasiriwong W, Puttanapong N, Saengsuwan J, Phajan T. Association between Socioeconomic Status and Diabetes Mellitus: The National Socioeconomics Survey, 2010 and 2012. J Clin Diagn Res. 2017;11(7):LC18-LC22.

5. Jones L, Bates G, McCoy E, Bellis MA. Relationship between alcohol-attributable disease and socioeconomic status, and the role of alcohol consumption in this relationship: a systematic review and meta-analysis. BMC Public Health. 2015;15:400.

6. Leng B, Jin Y, Li G, Chen L, Jin N. Socioeconomic status and hypertension: a meta-analysis. J Hypertens. 2015;33(2):221-9.

7. Zhang R, Deng R, Shen P, Fan M, Leng B, Zhou Y, et al. Prehypertension and socioeconomic status: A cross-sectional study in Chongqing, China. Clin Exp Hypertens. 2017;39(8):774-80.

8. Court-Brown CM, Aitken SA, Duckworth AD, Clement ND, McQueen MM. The relationship between social deprivation and the incidence of adult fractures. J Bone Joint Surg Am. 2013;95(6):e321-7.

9. Court-Brown CM, Aitken SA, Ralston SH, McQueen MM. The relationship of fall-related fractures to social deprivation. Osteoporos Int. 2011;22(4):1211-8.

10. Court-Brown CM, Brydone A. Social deprivation and adult tibial diaphyseal fractures. Injury. 2007;38(7):750-4.

11. Schultz WM, Kelli HM, Lisko JC, Varghese T, Shen J, Sandesara P, et al. Socioeconomic Status and Cardiovascular Outcomes: Challenges and Interventions. Circulation. 2018;137(20):2166-78.

12. Lochner KA, Saydah S. Socioeconomic status and risk of diabetes mortality in the US: 1990-2000. American Journal of Epidemiology. 2008;167(11):S44-S. 
13. Saydah S, Lochner K. Socioeconomic status and risk of diabetes-related mortality in the U.S. Public Health Rep. 2010;125(3):377-88.

14. Saydah SH, Imperatore G, Beckles GL. Socioeconomic status and mortality: contribution of health care access and psychological distress among U.S. adults with diagnosed diabetes. Diabetes Care. 2013;36(1):49-55.

15. Jepsen P, Vilstrup H, Andersen PK, Sorensen HT. Socioeconomic status and survival of cirrhosis patients: a Danish nationwide cohort study. BMC Gastroenterol. 2009;9:35.

16. Omland LH, Osler M, Jepsen P, Krarup H, Weis N, Christensen PB, et al. Socioeconomic status in HCV infected patients - risk and prognosis. Clin Epidemiol. 2013;5:163-72.

17. Barone AP, Fusco D, Colais P, D'Ovidio M, Belleudi V, Agabiti N, et al. Effects of socioeconomic position on 30-day mortality and wait for surgery after hip fracture. Int J Qual Health Care. 2009;21(6):379-86.

18. Clement ND, McQueen MM, Court-Brown CM. Social deprivation influences the epidemiology and outcome of proximal humeral fractures in adults for a defined urban population of Scotland. Eur $\mathrm{J}$ Orthop Surg Traumatol. 2014;24(7):1039-46.

19. Haines KL, Nguyen BP, Vatsaas C, Alger A, Brooks K, Agarwal SK. Socioeconomic Status Affects Outcomes After Severity-Stratified Traumatic Brain Injury. J Surg Res. 2019;235:131-40.

20. Haines KL, Woldanski LM, Zens T, Vatsaas C, Alger A, Brooks K, et al. The Impact of Race and Socioeconomic Status on Treatment and Outcomes of Blunt Splenic Injury. J Surg Res. 2019;240:609.

21. Lang SJ, Abel GA, Mant J, Mullis R. Impact of socioeconomic deprivation on screening for cardiovascular disease risk in a primary prevention population: a cross-sectional study. BMJ Open. 2016;6(3):e009984.

22. Bakens M, Lemmens V, de Hingh I. Socio-economic status influences the likelihood of undergoing surgical treatment for pancreatic cancer in the Netherlands. HPB (Oxford). 2017;19(5):443-8.

23. Patel AR, Sarkisova N, Smith R, Gupta K, VandenBerg CD. Socioeconomic status impacts outcomes following pediatric anterior cruciate ligament reconstruction. Medicine (Baltimore). 2019;98(17):e15361.

24. Govindarajan A, Schull M. Effect of socioeconomic status on out-of-hospital transport delays of patients with chest pain. Ann Emerg Med. 2003;41(4):481-90.

25. Addo J, Ayerbe L, Mohan KM, Crichton S, Sheldenkar A, Chen R, et al. Socioeconomic status and stroke: an updated review. Stroke. 2012;43(4):1186-91.

26. Duckworth AD, Clement ND, Jenkins PJ, Will EM, Court-Brown CM, McQueen MM. Socioeconomic deprivation predicts outcome following radial head and neck fractures. Injury. 2012;43(7):1102-6.

27. Jenkins PJ, Watts AC, Duckworth AD, McEachan JE. Socioeconomic deprivation and the epidemiology of carpal tunnel syndrome. J Hand Surg Eur Vol. 2012;37(2):123-9. 
28. Paksima N, Pahk B, Romo S, Egol KA. The association of education level on outcome after distal radius fracture. Hand (N Y). 2014;9(1):75-9.

29. Finsen V. The influence of education and income on responses to the QuickDASH questionnaire. J Hand Surg Eur Vol. 2015;40(4):401-5.

30. Okoroafor UC, Gerull W, Wright M, Guattery J, Sandvall B, Calfee RP. The Impact of Social Deprivation on Pediatric PROMIS Health Scores After Upper Extremity Fracture. J Hand Surg Am. 2018;43(10):897-902.

31. Wright MA, Adelani M, Dy C, O'Keefe R, Calfee RP. What is the Impact of Social Deprivation on Physical and Mental Health in Orthopaedic Patients? Clin Orthop Relat Res. 2019;477(8):1825-35.

32. Moret L, Anthoine E, Pourreau A, Beaudeau F, Leclere B. Inpatient satisfaction with medical information received from caregivers: an observational study on the effect of social deprivation. BMC Health Serv Res. 2017;17(1):769.

33. Paddison CA, Abel GA, Roland MO, Elliott MN, Lyratzopoulos G, Campbell JL. Drivers of overall satisfaction with primary care: evidence from the English General Practice Patient Survey. Health Expect. 2015;18(5):1081-92.

34. Haviland MG, Morales LS, Dial TH, Pincus HA. Race/ethnicity, socioeconomic status, and satisfaction with health care. Am J Med Qual. 2005;20(4):195-203.

35. Owolabi O, Zhang Z, Wei X, Yang N, Li H, Wong SY, et al. Patients' socioeconomic status and their evaluations of primary care in Hong Kong. BMC Health Serv Res. 2013;13:487.

36. Myburgh NG, Solanki GC, Smith MJ, Lalloo R. Patient satisfaction with health care providers in South Africa: the influences of race and socioeconomic status. Int J Qual Health Care. 2005;17(6):473-7.

37. Campbell JL, Ramsay J, Green J. Age, gender, socioeconomic, and ethnic differences in patients' assessments of primary health care. Qual Health Care. 2001;10(2):90-5.

38. McFarland DC, Ornstein KA, Holcombe RF. Demographic factors and hospital size predict patient satisfaction variance-implications for hospital value-based purchasing. J Hosp Med. 2015;10(8):503-9.

39. Presson AP, Zhang C, Abtahi AM, Kean J, Hung M, Tyser AR. Psychometric properties of the Press Ganey(R) Outpatient Medical Practice Survey. Health Qual Life Outcomes. 2017;15(1):32.

40. Nieman CL, Benke JR, Boss EF. Does Race/Ethnicity or Socioeconomic Status Influence Patient Satisfaction in Pediatric Surgical Care? Otolaryngol Head Neck Surg. 2015;153(4):620-8.

41. Rane AA, Tyser AR, Presson AP, Zhang C, Kazmers NH. Patient Satisfaction in the Hand Surgery Clinic: An Analysis of Factors That Impact the Press Ganey Survey. J Hand Surg Am. 2019;44(7):539$47 \mathrm{e} 1$.

42. Press Ganey 2019;Pageshttp://healthcare.pressganey.com/Transparency-Data-StandardEndorsement?elqCampaignld $=1078$ on 9/5/2019.

43. University of Wisconsin School of Medicine and Public Health 2015;Pageshttps://www.neighborhoodatlas.medicine.wisc.edu/ on Sep 9, 2019. 
44. Kind AJH, Buckingham WR. Making Neighborhood-Disadvantage Metrics Accessible - The Neighborhood Atlas. N Engl J Med. 2018;378(26):2456-8.

45. United States Census Bureau Geograph Divison 2019;Pageshttps://www.census.gov/programssurveys/geography.html on Sep 9, 2019.

46. Kind AJ, Jencks S, Brock J, Yu M, Bartels C, Ehlenbach W, et al. Neighborhood socioeconomic disadvantage and 30-day rehospitalization: a retrospective cohort study. Ann Intern Med. 2014;161(11):765-74.

47. Singh GK. Area deprivation and widening inequalities in US mortality, 1969-1998. Am J Public Health. 2003;93(7):1137-43.

48. Wright MA, Beleckas CM, Calfee RP. Mental and Physical Health Disparities in Patients With Carpal Tunnel Syndrome Living With High Levels of Social Deprivation. J Hand Surg Am. 2019;44(4):335 e1e9.

49. Durfey SNM, Kind AJH, Buckingham WR, DuGoff EH, Trivedi AN. Neighborhood disadvantage and chronic disease management. Health Serv Res. 2019;54 Suppl 1:206-16.

50. Hu J, Kind AJH, Nerenz D. Area Deprivation Index Predicts Readmission Risk at an Urban Teaching Hospital. Am J Med Qual. 2018;33(5):493-501.

51. Jencks SF, Schuster A, Dougherty GB, Gerovich S, Brock JE, Kind AJH. Safety-Net Hospitals, Neighborhood Disadvantage, and Readmissions Under Maryland's All-Payer Program: An Observational Study. Ann Intern Med. 2019;171(2):91-8.

52. Jung D, Kind A, Robert S, Buckingham W, DuGoff E. Linking Neighborhood Context and Health in Community-Dwelling Older Adults in the Medicare Advantage Program. J Am Geriatr Soc. 2018;66(6):1158-64.

53. Lantos PM, Hoffman K, Permar SR, Jackson P, Hughes BL, Kind A, et al. Neighborhood Disadvantage is Associated with High Cytomegalovirus Seroprevalence in Pregnancy. J Racial Ethn Health Disparities. 2018;5(4):782-6.

54. Sheets L, Petroski GF, Jaddoo J, Barnett Y, Barnett C, Kelley LEH, et al. The Effect of Neighborhood Disadvantage on Diabetes Prevalence. AMIA Annu Symp Proc. 2017;2017:1547-53.

55. Abtahi AM, Presson AP, Zhang C, Saltzman CL, Tyser AR. Association Between Orthopaedic Outpatient Satisfaction and Non-Modifiable Patient Factors. J Bone Joint Surg Am. 2015;97(13):1041-8.

56. Tyser AR, Abtahi AM, McFadden M, Presson AP. Evidence of non-response bias in the Press-Ganey patient satisfaction survey. BMC Health Serv Res. 2016;16(a):350.

57. Rane AT, AR; Kazmers, NH. Evaluating the Impact of Wait Time on Orthopaedic Outpatient Satisfaction Using the Press Ganey Survey. Journal of Bone and Joint Surgery - Open Access. 2019.

58. Tyser AR, Gaffney CJ, Zhang C, Presson AP. The Association of Patient Satisfaction with Pain, Anxiety, and Self-Reported Physical Function. J Bone Joint Surg Am. 2018;100(21):1811-8. 
59. Lantos PM, Maradiaga-Panayotti G, Barber X, Raynor E, Tucci D, Hoffman K, et al. Geographic and Racial Disparities in Infant Hearing Loss. Otolaryngol Head Neck Surg. 2018:194599818803305.

60. Clark AM, DesMeules M, Luo W, Duncan AS, Wielgosz A. Socioeconomic status and cardiovascular disease: risks and implications for care. Nat Rev Cardiol. 2009;6(11):712-22.

61. Young GJ, Meterko M, Desai KR. Patient satisfaction with hospital care: effects of demographic and institutional characteristics. Med Care. 2000;38(3):325-34.

62. Arpey NC, Gaglioti AH, Rosenbaum ME. How Socioeconomic Status Affects Patient Perceptions of Health Care: A Qualitative Study. J Prim Care Community Health. 2017;8(3):169-75.

63. Kangovi S, Barg FK, Carter T, Long JA, Shannon R, Grande D. Understanding why patients of low socioeconomic status prefer hospitals over ambulatory care. Health Aff (Millwood). 2013;32(7):1196-203.

64. Kangovi S, Levy K, Barg FK, Carter T, Long JA, Grande D. Perspectives of older adults of low socioeconomic status on the post-hospital transition. J Health Care Poor Underserved. 2014;25(2):746-56.

65. Mehta PK, Carter T, Vinoya C, Kangovi S, Srinivas SK. Understanding High Utilization of Unscheduled Care in Pregnant Women of Low Socioeconomic Status. Womens Health Issues. 2017;27(4):441-8.

66. Verlinde E, De Laender N, De Maesschalck S, Deveugele M, Willems S. The social gradient in doctorpatient communication. Int J Equity Health. 2012;11:12.

67. Schroder SL, Fink A, Richter M. Socioeconomic differences in experiences with treatment of coronary heart disease: a qualitative study from the perspective of elderly patients. BMJ Open. 2018;8(11):e024151.

68. Tisano BK, Nakonezny PA, Gross BS, Martinez JR, Wells JE. Depression and Non-modifiable Patient Factors Associated with Patient Satisfaction in an Academic Orthopaedic Outpatient Clinic: Is it More Than a Provider Issue? Clin Orthop Relat Res. 2019.

69. Schroder SL, Fink A, Hoffmann L, Schumann N, Martin O, Frantz S, et al. Socioeconomic differences in the pathways to diagnosis of coronary heart disease: a qualitative study. Eur J Public Health. 2017;27(6):1055-60.

70. Agarwal N, Faramand A, Bellon J, Borrebach J, Hamilton DK, Okonkwo DO, et al. Limitations of patient experience reports to evaluate physician quality in spine surgery: analysis of 7485 surveys. J Neurosurg Spine. 2019:1-4.

71. Kerr EA, Smith DM, Kaplan SH, Hayward RA. The association between three different measures of health status and satisfaction among patients with diabetes. Med Care Res Rev. 2003;60(2):158-77.

72. Korman NJ, Zhao Y, Lu J, Tran MH. Psoriasis disease severity affects patient satisfaction with treatment. Dermatol Online J. 2015;21(7).

73. Merlino JI, Kestranek C, Bokar D, Sun Z, Nissen SE, Longworth DL. HCAHPS Survey Results: Impact of Severity of Illness on Hospitals' Performance on HCAHPS Survey Results. J Patient Exp. 2014;1(2):16-21. 
74. Centers for Medicare and Medicaid Services 2018;Pageshttps://www.cms.gov/Medicare/QualityInitiatives-Patient-Assessment-Instruments/Value-Based-Programs/HVBP/Hospital-Value-BasedPurchasing.html.

75. Scott A, Sivey P, Ait Ouakrim D, Willenberg L, Naccarella L, Furler J, et al. The effect of financial incentives on the quality of health care provided by primary care physicians. Cochrane Database Syst Rev. 2011(9):CD008451.

76. Advisory Board;Pageshttps://www.advisory.com/daily-briefing/2017/08/07/hospital-penalties on Sep 11, 2019.

77. U.S. Food and Drug Administration 2018;Pageshttps://www.fda.gov/regulatoryinformation/selected-amendments-fdc-act/21st-century-cures-actSep 11, 2019.

78. Joynt Maddox KE, Reidhead M, Qi AC, Nerenz DR. Association of Stratification by Dual Enrollment Status With Financial Penalties in the Hospital Readmissions Reduction Program. JAMA Intern Med. 2019.

79. Michel M, Alberti C, Carel JC, Chevreul K. Association of Pediatric Inpatient Socioeconomic Status With Hospital Efficiency and Financial Balance. JAMA Netw Open. 2019;2(10):e1913656.

\section{Tables}

Table 1 - Baseline Patient Characteristics 


\begin{tabular}{|c|c|c|}
\hline Factor & \multicolumn{2}{|c|}{$\begin{array}{c}\text { Value } \\
(\mathrm{n}=59,955)\end{array}$} \\
\hline \multicolumn{3}{|l|}{ Demographics } \\
\hline Age (mean years $(\mathrm{SD})$ ) & 51.7 & $(17.1)$ \\
\hline Area Deprivation Index (National Percentile) & 30.8 & $(19.2)$ \\
\hline \multicolumn{3}{|l|}{ Race } \\
\hline White & 54251 & $(90.5 \%)$ \\
\hline Other & 2491 & $(4.2 \%)$ \\
\hline Asian & 1391 & $(2.3 \%)$ \\
\hline Black or African American & 437 & $(0.7 \%)$ \\
\hline American Indian / Native Alaskan & 250 & $(0.4 \%)$ \\
\hline Native Hawaiian/Pacific Islander & 277 & $(0.5 \%)$ \\
\hline Unknown & 858 & $(1.4 \%)$ \\
\hline Sex (female) & 38330 & $(63.9 \%)$ \\
\hline \multicolumn{3}{|l|}{ Insurance } \\
\hline Medicaid & 943 & $(1.6 \%)$ \\
\hline Medicare & 14376 & $(24.1 \%)$ \\
\hline Other government (IHS, VA) & 8123 & $(13.6 \%)$ \\
\hline Commercial & 36033 & $(60.5 \%)$ \\
\hline Workers' Compensation & 137 & $(0.22 \%)$ \\
\hline \multicolumn{3}{|l|}{ Visit Characteristics } \\
\hline \multicolumn{3}{|l|}{ Press Ganey Scores } \\
\hline \multicolumn{3}{|l|}{ Total Score } \\
\hline Mean (SD) & 91.4 & $(11.9)$ \\
\hline 33rd percentile & \multicolumn{2}{|c|}{91.7} \\
\hline \multicolumn{3}{|l|}{ Provider Sub-Score } \\
\hline Mean (SD) & 93.1 & $(14.8)$ \\
\hline 33rd percentile & \multicolumn{2}{|c|}{97.5} \\
\hline \multicolumn{3}{|l|}{ Specialty Type } \\
\hline Internal Medicine & 10552 & $(17.6 \%)$ \\
\hline Medicine Other & 26748 & $(44.6 \%)$ \\
\hline Surgical & 22655 & $(37.8 \%)$ \\
\hline \multicolumn{3}{|l|}{ Provider Type } \\
\hline Nurse & 2944 & $(4.9 \%)$ \\
\hline Other & 3456 & $(5.8 \%)$ \\
\hline Physician Assistant & 5654 & $(9.4 \%)$ \\
\hline Physician & 47878 & $(79.9 \%)$ \\
\hline Unknown & 23 & $(0.0 \%)$ \\
\hline
\end{tabular}


Continuous data presented as mean \pm standard deviation; categorical data presented as number of patients and (percentage). Abbreviations: HIS - Indian Health Service; SD - standard deviation; VA - Veterans Affairs.

Table 2 - Univariate Analysis for the Press Ganey Total Score 


\begin{tabular}{|c|c|c|c|c|c|}
\hline \multirow[b]{2}{*}{ Factor } & \multicolumn{2}{|c|}{ Odds Ratio (OR) } & \multirow[b]{2}{*}{ Coefficient } & \multirow[b]{2}{*}{$\begin{array}{c}\text { Coefficient Standard } \\
\text { Error }\end{array}$} & \multirow[b]{2}{*}{$\begin{array}{l}\text { P - } \\
\text { Value }\end{array}$} \\
\hline & OR & $\begin{array}{c}95 \% \\
\text { Confidence } \\
\text { Interval }\end{array}$ & & & \\
\hline Age* & 1.061 & $\begin{array}{l}(1.055 \bullet \\
1.066) \\
\end{array}$ & 0.012 & 0.0005 & $<0.001$ \\
\hline Area Deprivation Index $^{\dagger}$ & 0.956 & $\begin{array}{l}(0.948 \bullet \\
0.965) \\
\end{array}$ & -0.004 & 0.0004 & $<0.001$ \\
\hline Insurance & & - & - & - & - \\
\hline Commercial & $\begin{array}{l}\text { Reference } \\
\text { Category }\end{array}$ & - & - & - & - \\
\hline Medicaid & 0.743 & $(0.652 \cdot 0.847)$ & -0.297 & 0.066 & $<0.001$ \\
\hline Medicare & 1.341 & $(1.286 \cdot 1.398)$ & 0.293 & 0.021 & $<0.001$ \\
\hline Other Government Insurance & 1.098 & $(1.044 \cdot 1.155)$ & 0.093 & 0.026 & $<0.001$ \\
\hline Workers' Compensation & 0.687 & $\begin{array}{l}(0.490 \bullet \\
0.963) \\
\end{array}$ & -0.376 & 0.173 & 0.029 \\
\hline Race & & - & - & - & $0.001^{\ddagger}$ \\
\hline White & $\begin{array}{l}\text { Reference } \\
\text { Category }\end{array}$ & - & - & - & - \\
\hline Other & 0.867 & $\begin{array}{l}(0.798 \bullet \\
0.942) \\
\end{array}$ & -0.143 & 0.042 & 0.001 \\
\hline Asian & 0.608 & $\begin{array}{l}(0.546 \bullet \\
0.676)\end{array}$ & -0.498 & 0.055 & $<0.001$ \\
\hline Black or African American & 0.761 & $\begin{array}{l}(0.629 \bullet \\
0.922)\end{array}$ & -0.273 & 0.098 & 0.005 \\
\hline American Indian and Alaska Native & 0.688 & $\begin{array}{l}(0.535 \bullet \\
0.884)\end{array}$ & -0.374 & 0.128 & 0.003 \\
\hline $\begin{array}{l}\text { Native Hawaiian and Other Pacific } \\
\text { Islander }\end{array}$ & 1.162 & $\begin{array}{l}(0.900 \bullet \\
1.500)\end{array}$ & 0.150 & 0.130 & 0.25 \\
\hline \multicolumn{6}{|l|}{ Sex } \\
\hline Female & $\begin{array}{l}\text { Reference } \\
\text { Category }\end{array}$ & - & F- & - & - \\
\hline Male & 1.043 & $\begin{array}{l}(1.001 \bullet \\
1.080) \\
\end{array}$ & 0.042 & 0.018 & 0.020 \\
\hline Provider Type & - & $\overline{-}$ & - & - & $<0.001 \mathrm{c}$ \\
\hline Physician & $\begin{array}{l}\text { Reference } \\
\text { Category }\end{array}$ & - & - & - & - \\
\hline Nurse & 1.018 & $\begin{array}{l}(0.942 \bullet \\
1.101)\end{array}$ & 0.018 & 0.040 & 0.65 \\
\hline Other & 1.069 & $\begin{array}{l}(0.994 \bullet \\
1.150)\end{array}$ & 0.066 & 0.037 & 0.074 \\
\hline Physician Assistant & 0.999 & $\begin{array}{l}(0.943 \bullet \\
1.059) \\
\end{array}$ & -0.001 & 0.030 & 0.98 \\
\hline \multicolumn{6}{|l|}{ Specialty Type } \\
\hline Internal Medicine & $\begin{array}{l}\text { Reference } \\
\text { Category }\end{array}$ & - & & & \\
\hline Medicine Other & 1.001 & $\begin{array}{l}(0.954 \bullet \\
1.049)\end{array}$ & 0.001 & 0.024 & 0.99 \\
\hline Surgical & 0.960 & $\begin{array}{l}(0.9143 \bullet \\
1.008)\end{array}$ & -0.041 & 0.025 & 0.097 \\
\hline Wait Time ${ }^{\S}$ & 0.766 & $\begin{array}{l}(0.760 \bullet \\
0.772)\end{array}$ & -0.053 & 0.001 & $<0.001$ \\
\hline
\end{tabular}

*Per 5 years of additional age.

${ }^{\dagger}$ Per additional 10 percentile points.

${ }^{\ddagger} \mathrm{P}$-values for the overall univariate binary logistic regression model. Subsequent p-values listed are for pairwise comparisons.

§er additional 5 minutes. 
Table 3 - Univariate Analysis for the Press Ganey Provider Sub-Score

\begin{tabular}{|c|c|c|c|c|c|}
\hline \multirow[b]{2}{*}{ Factor } & \multicolumn{2}{|c|}{ Odds Ratio (OR) } & \multirow[b]{2}{*}{ Coefficient } & \multirow{2}{*}{$\begin{array}{c}\text { Coefficient } \\
\text { Standard Error }\end{array}$} & \multirow[b]{2}{*}{$\begin{array}{l}\mathrm{P} \text { - } \\
\text { Value }\end{array}$} \\
\hline & OR & $\begin{array}{l}95 \% \\
\quad \text { Confidence } \\
\text { Interval }\end{array}$ & & & \\
\hline Age* & 1.052 & $(1.047 \cdot 1.057)$ & 0.010 & 0.001 & $\begin{array}{l} \\
0.001 \\
\end{array}$ \\
\hline Area Deprivation Index ${ }^{\dagger}$ & 0.953 & $(0.945 \cdot 0.961)$ & -0.005 & $<0.001$ & $\begin{array}{l}< \\
0.001 \\
\end{array}$ \\
\hline Insurance & - & - & - & - & - \\
\hline Commercial & $\begin{array}{l}\text { Reference } \\
\text { Category }\end{array}$ & - & - & - & - \\
\hline Medicaid & 0.798 & $(0.700 \cdot 0.911)$ & -0.225 & 0.067 & 0.001 \\
\hline Medicare & 1.255 & $(1.204 \cdot 1.308)$ & 0.227 & 0.021 & $<0.001$ \\
\hline Other Government Insurance & 1.130 & $(1.074 \cdot 1.189)$ & 0.122 & 0.026 & $<0.001$ \\
\hline Workers' Compensation & 0.829 & $(0.589 \cdot 1.169)$ & -0.187 & 0.175 & 0.29 \\
\hline Race & - & - & - & - & $0.001^{\ddagger}$ \\
\hline White & $\begin{array}{l}\text { Reference } \\
\text { Category }\end{array}$ & - & - & - & - \\
\hline Other & 0.900 & $(0.828 \cdot 0.978)$ & -0.106 & 0.043 & 0.99 \\
\hline Asian & 0.706 & $(0.634 \cdot 0.787)$ & -0.348 & 0.055 & $<0.001$ \\
\hline Black or African American & 0.783 & $(0.646 \cdot 0.949)$ & -0.245 & 0.098 & 0.013 \\
\hline American Indian and Alaska Native & 0.801 & $(0.621 \cdot 1.034)$ & -0.222 & 0.130 & 0.088 \\
\hline $\begin{array}{l}\text { Native Hawaiian and Other Pacific } \\
\text { Islander }\end{array}$ & 1.274 & $(0.982 \cdot 1.653)$ & 0.242 & 0.133 & 0.069 \\
\hline Sex & & - & - & - & - \\
\hline Female & $\begin{array}{l}\text { Reference } \\
\text { Category }\end{array}$ & - & - & - & - \\
\hline Male & 0.978 & $(0.945 \cdot 1.013)$ & -0.022 & 0.018 & 0.21 \\
\hline Provider Type & - & - & - & - & $\begin{array}{l} \\
0.001 c\end{array}$ \\
\hline Physician & $\begin{array}{l}\text { Reference } \\
\text { Category }\end{array}$ & - & - & - & - \\
\hline Nurse & 1.256 & $(1.158 \cdot 1.362)$ & 0.228 & 0.041 & $\begin{array}{l} \\
0.001 \\
\end{array}$ \\
\hline Other & 1.280 & $(1.187 \cdot 1.381)$ & 0.247 & 0.039 & $\begin{array}{l} \\
0.001 \\
\end{array}$ \\
\hline Physician Assistant & 0.970 & $(0.913 \cdot 1.024)$ & -0.034 & 0.029 & 0.25 \\
\hline \multicolumn{6}{|l|}{ Specialty Type } \\
\hline Internal Medicine & $\begin{array}{l}\text { Reference } \\
\text { Category }\end{array}$ & - & - & - & - \\
\hline Medicine Other & 0.947 & $(0.903 \cdot 0.993)$ & -0.055 & 0.024 & 0.025 \\
\hline Surgical & 0.886 & $(0.843 \cdot 0.930)$ & -0.121 & 0.025 & $\begin{array}{l}< \\
0.001 \\
\end{array}$ \\
\hline Wait Timed & 0.883 & $(0.878 \cdot 0.889)$ & -0.025 & 0.001 & $<0.001$ \\
\hline
\end{tabular}

*Per 5 years of additional age.

${ }^{\dagger}$ Per additional 10 percentile points.

${ }^{\ddagger} \mathrm{P}$-values for the overall univariate binary logistic regression model. Subsequent p-values listed are for pairwise comparisons.

§Per additional 5 minutes

Table 4 - Multivariable Analysis for the Press Ganey Total Score 


\begin{tabular}{|c|c|c|c|c|c|}
\hline \multirow[b]{2}{*}{ Factor ${ }^{*}$} & \multicolumn{2}{|c|}{ Odds Ratio (OR) } & \multirow[b]{2}{*}{ Coefficient } & \multirow{2}{*}{$\begin{array}{c}\text { Coefficient } \\
\text { Standard Error }\end{array}$} & \multirow[b]{2}{*}{$\begin{array}{l}\text { P - } \\
\text { Value }\end{array}$} \\
\hline & OR & $\begin{array}{l}\text { 95\% Confidence } \\
\text { Interval }\end{array}$ & & & \\
\hline $\mathrm{Age}^{\dagger}$ & 1.063 & $(1.056 \cdot 1.071)$ & 0.012 & 0.001 & $\begin{array}{l}< \\
0.001 \\
\end{array}$ \\
\hline Area Deprivation Indexc & 0.976 & $(0.967 \bullet 0.985)$ & -0.002 & $<0.001$ & $\begin{array}{l}< \\
0.001\end{array}$ \\
\hline Insurance & & - & - & - & - \\
\hline Commercial & $\begin{array}{l}\text { Reference } \\
\text { Category }\end{array}$ & - & - & - & - \\
\hline Medicaid & 0.901 & $(0.783 \cdot 1.037)$ & -0.104 & 0.072 & 0.147 \\
\hline Medicare & 1.034 & $(0.978 \cdot 1.092)$ & 0.033 & 0.028 & 0.24 \\
\hline Other Government Insurance & 1.132 & $(1.072 \cdot 1.195)$ & 0.124 & 0.028 & $<0.001$ \\
\hline Workers' Compensation & 0.821 & $(0.570 \cdot 1.182)$ & -0.197 & 0.186 & 0.29 \\
\hline Race & & - & - & - & $0.001^{\ddagger}$ \\
\hline White & $\begin{array}{l}\text { Reference } \\
\text { Category }\end{array}$ & - & - & - & - \\
\hline Other & 1.031 & $(0.943 \cdot 1.127)$ & 0.031 & 0.046 & 0.50 \\
\hline Asian & 0.669 & $(0.597 \cdot 0.750)$ & -0.402 & 0.058 & $<0.001$ \\
\hline Black or African American & 0.938 & $(0.763 \cdot 1.153)$ & -0.064 & 0.105 & 0.54 \\
\hline $\begin{array}{l}\text { American Indian and Alaska } \\
\text { Native }\end{array}$ & 0.794 & $(0.607 \cdot 1.039)$ & -0.231 & 0.137 & 0.093 \\
\hline $\begin{array}{l}\text { Native Hawaiian and Other } \\
\text { Pacific Islander }\end{array}$ & 1.274 & $(1.064 \cdot 1.838)$ & 0.335 & 0.139 & 0.016 \\
\hline Sex & & - & - & - & - \\
\hline Female & $\begin{array}{l}\text { Reference } \\
\text { Category }\end{array}$ & - & - & - & - \\
\hline Male & 0.956 & $(0.921 \cdot 0.994)$ & -0.045 & 0.019 & 0.022 \\
\hline Provider Type & & & T- & - & $\begin{array}{l}< \\
0.001^{\S}\end{array}$ \\
\hline Physician & $\begin{array}{l}\text { Reference } \\
\text { Category }\end{array}$ & & †- & - & - \\
\hline Nurse & 0.973 & $(0.896 \cdot 1.056)$ & -0.028 & 0.042 & 0.51 \\
\hline Other & 0.853 & $(0.789 \cdot 0.921)$ & -0.159 & 0.039 & $\begin{array}{l} \\
0.001\end{array}$ \\
\hline Physician Assistant & 1.023 & $(0.962 \cdot 1.088)$ & 0.022 & 0.031 & 0.48 \\
\hline Wait Time $^{\|}$ & 0.764 & $(0.878 \cdot 0.889)$ & -0.054 & 0.001 & $<0.001$ \\
\hline
\end{tabular}

*Specialty type was included as a predictor in the model, but was insignificant based on a backward step-wise term selection threshold of $\alpha=0.10$.

${ }^{\dagger}$ Per 5 years of additional age.

₹Per additional 10 percentile points.

\$P-values for the overall univariate binary logistic regression model. Subsequent p-values listed are for pairwise comparisons.

"Per additional 5 minutes.

Table 5 - Multivariable Analysis for the Press Ganey Provider Sub-Score 


\begin{tabular}{|c|c|c|c|c|c|}
\hline \multirow[b]{2}{*}{ Factor* } & \multicolumn{2}{|c|}{ Odds Ratio (OR) } & \multirow[b]{2}{*}{ Coefficient } & \multirow{2}{*}{$\begin{array}{l}\text { Coefficient } \\
\text { Standard Error }\end{array}$} & \multirow[b]{2}{*}{$\begin{array}{l}P \text { - } \\
\text { Value }\end{array}$} \\
\hline & OR & $\begin{array}{l}95 \% \text { Confidence } \\
\text { Interval } \\
\end{array}$ & & & \\
\hline $\operatorname{Age}^{\dagger}$ & 1.061 & $(1.054 \cdot 1.068)$ & 0.012 & 0.001 & $\begin{array}{l}< \\
0.001\end{array}$ \\
\hline Area Deprivation Indexc & 0.967 & $(0.958 \cdot 0.976)$ & -0.003 & $<0.001$ & $\begin{array}{l} \\
0.001\end{array}$ \\
\hline Insurance & & - & T- & T- & T- \\
\hline Commercial & $\begin{array}{l}\text { Reference } \\
\text { Category }\end{array}$ & - & - & - & - \\
\hline Medicaid & 0.927 & $(0.809 \cdot 1.062)$ & -0.076 & 0.069 & 0.27 \\
\hline Medicare & 0.973 & $(0.922 \cdot 1.026)$ & -0.028 & 0.027 & 0.30 \\
\hline Other Government Insurance & 1.156 & $(1.097 \cdot 1.219)$ & 0.145 & 0.027 & $<0.001$ \\
\hline Workers' Compensation & 1.000 & $(0.703 \cdot 1.423)$ & $<-0.001$ & 0.180 & 1.000 \\
\hline Race & & - & - & - & $0.001^{\ddagger}$ \\
\hline White & $\begin{array}{l}\text { Reference } \\
\text { Category }\end{array}$ & - & - & - & - \\
\hline Other & 1.025 & $(0.940 \cdot 1.117)$ & 0.025 & 0.044 & 0.58 \\
\hline Asian & 0.767 & $(0.686 \cdot 0.857)$ & -0.266 & 0.057 & $<0.001$ \\
\hline Black or African American & 0.911 & $(0.747 \cdot 1.112)$ & -0.093 & 0.102 & 0.36 \\
\hline $\begin{array}{l}\text { American Indian and Alaska } \\
\text { Native }\end{array}$ & 0.889 & $(0.684 \cdot 1.155)$ & -0.118 & 0.134 & 0.38 \\
\hline $\begin{array}{l}\text { Native Hawaiian and Other } \\
\text { Pacific Islander }\end{array}$ & 1.469 & $(1.125 \cdot 1.919)$ & 0.385 & 0.136 & 0.005 \\
\hline$\overline{\text { Sex }}$ & & T- & T- & T- & $T-$ \\
\hline Female & $\begin{array}{l}\text { Reference } \\
\text { Category }\end{array}$ & - & - & - & - \\
\hline Male & 0.917 & $(0.884 \cdot 0.952)$ & -0.087 & 0.019 & $<0.001$ \\
\hline Provider Type & & - & - & - & $\begin{array}{l}< \\
0.001^{\S}\end{array}$ \\
\hline Physician & $\begin{array}{l}\text { Reference } \\
\text { Category }\end{array}$ & - & - & - & - \\
\hline Nurse & 1.218 & $(1.120 \cdot 1.324)$ & 0.197 & 0.043 & $\begin{array}{l}< \\
0.001 \\
\end{array}$ \\
\hline Other & 1.264 & $(1.166 \cdot 1.370)$ & 0.234 & 0.041 & $\begin{array}{l}< \\
0.001\end{array}$ \\
\hline Physician Assistant & 0.977 & $(0.920 \cdot 1.037)$ & -0.023 & 0.031 & 0.44 \\
\hline Wait Time" & 0.886 & $(0.881 \cdot 0.891)$ & -0.024 & 0.001 & $<0.001$ \\
\hline
\end{tabular}

*Specialty type was included as a predictor in the model, but was insignificant based on a backward step-wise term selection threshold of $\alpha=0.10$.

${ }^{\dagger}$ Per 5 years of additional age.

‡Per additional 10 percentile points.

$\S$ P-values for the overall univariate binary logistic regression model. Subsequent p-values listed are for pairwise comparisons.

"Per additional 5 minutes

\section{Figures}


Figure 1

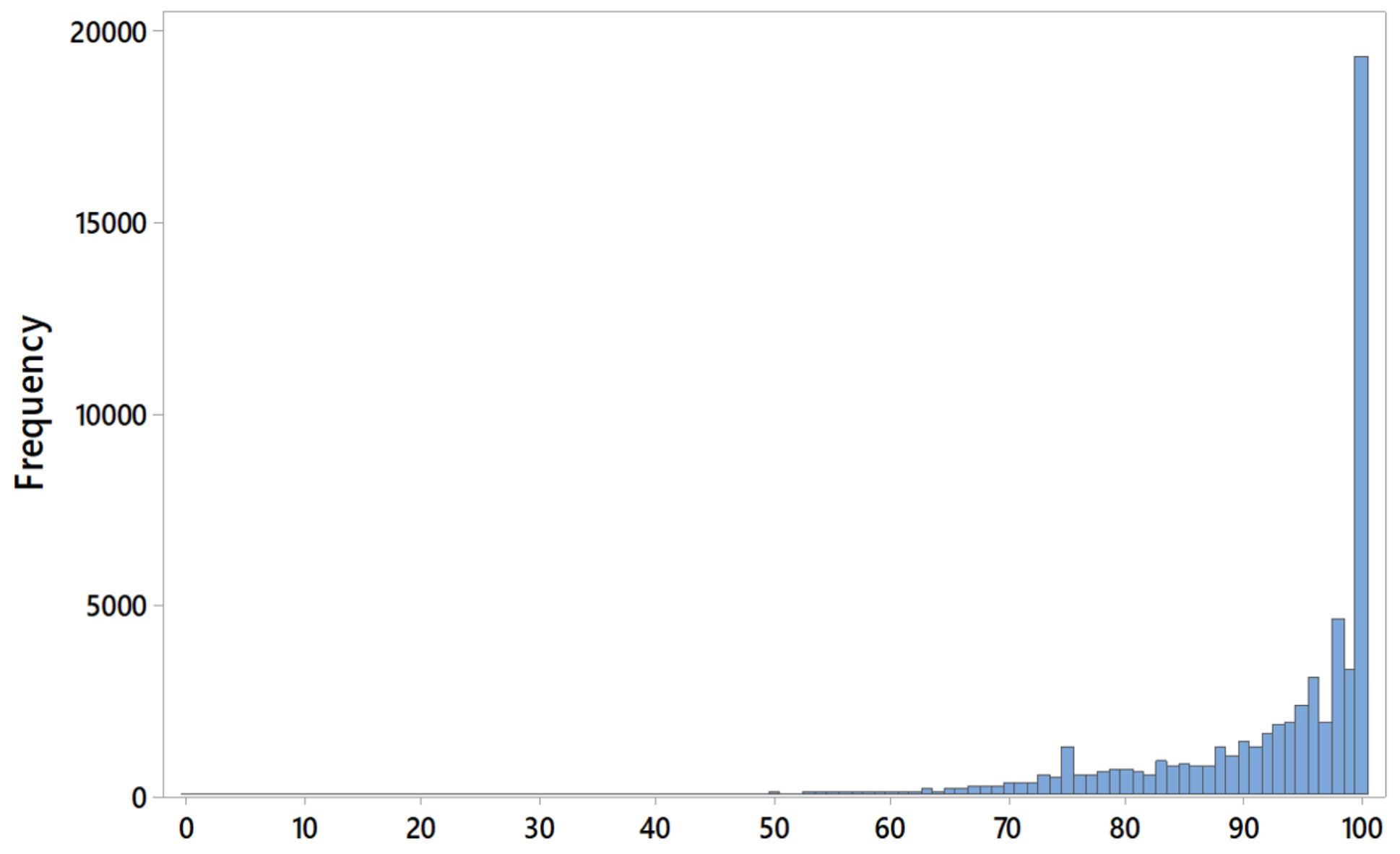

Figure 1

Histogram for the Press Ganey Total Score 
Figure 2

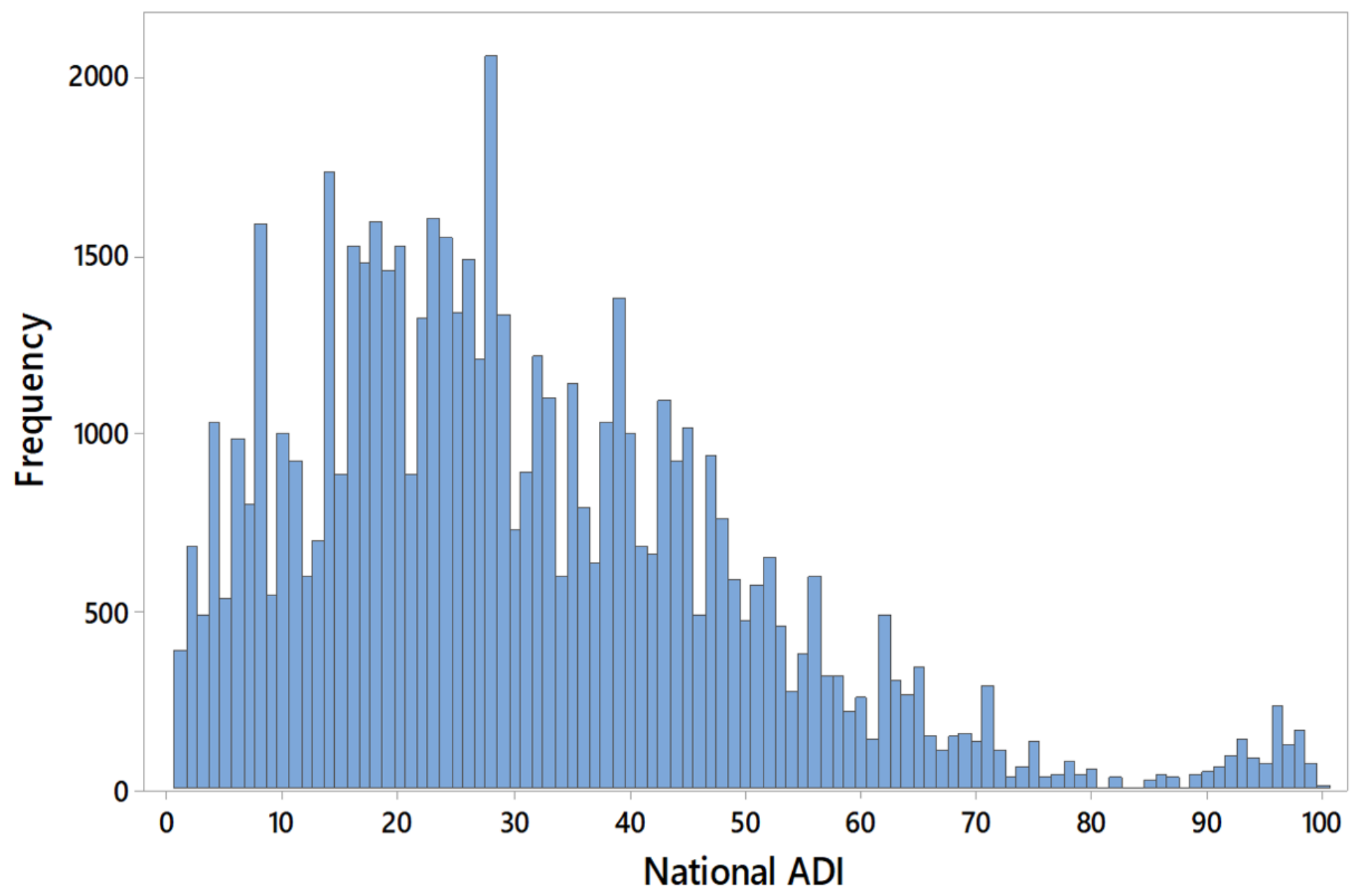

Figure 2

Histogram of Area Deprivation Index values

\section{Supplementary Files}

This is a list of supplementary files associated with this preprint. Click to download.

- AppendixTable1.docx 